\title{
Knowledge Attitude and Practices (KAP) towards child marriage among married women residing in Nandyal - A Qualitative study
}

\author{
B.Sumalatha ${ }^{1}$, M.A.Mushtaq Pasha ${ }^{2}$, Afsar Fatima ${ }^{3}$, Isaac Ebenezer ${ }^{4}$, \\ D.Surendra $\mathrm{babu}^{5}$
}

\begin{abstract}
:
Background: Globally, child marriage (CM) is defined as marriage before the age of 18 years which applies to both boys and girls (1).However in India, as per 'Prohibition of Child Marriage Act 2006', a marriage is legally considered as CM when girl is less than 18 years old or boy is less than21 years old.(2) In 2007, United Nations Children's Fund (UNICEF) reported that a girl under the age of15 is five times more likely to die during pregnancy and childbirth than a woman in her 20s(3) Most importantly, early marriage bereaves young girls of their childhood by overburdening them with domestic responsibility, motherhood, and sexual relations rather than allowing them to play with friends, go to school, and dream about a career (4)

Aims and objectives: Our aim is to assess women's knowledge and attitude towards child marriage practice who married before 18 years. To know the association between the child marriages and their consequences Methods: A community based cross sectional study was conducted among women residing in urban slums of Nandyal. Anin-depth interview wasconducted with 30 pre-identified married women of reproductive age (15-49 years). The criteria for selection of participants was those woman who married before the age of 18 years (child marriage) and married for at least 5 years and had at least one child birth. Reasons for setting the said selection criteria were to make sure that the interviewee had a prenatal and postnatal experience that they have spent a considerable time in marital union.

Results: Among 30 participants the mean age of child marriage is 14 years. Mean age at first child birth is $15 y e a r s$. Majority (86.7\%) were stopped education after marriage. According to Modified Kuppuswamy class $63.3 \%$ were belong to upper lower class \& $13.3 \%$ lower class. Almost (56.7\%) unaware of appropriate age for marriage. Majority (73.3\%) are unaware of negative consequences of child marriage. Most of the marriages are consanguineous (40\%). Majority (60\%) are home deliveries and pre term deliveries (46\%). Majority (73.3\%) are opposing child marriage and $26.7 \%$ are supporting child marriage and having future intention. Satisfied with their married life $60 \%$ and $40 \%$ participants are having conflicts

Conclusions: Raising the level of awareness about negative outcomes of child marriage by intensifying the Health education (IEC) activities. In this modern society the child marriages are following because of the customs and traditions followed in the community. Home deliveries are more which utmost leads to danger to the mother and child.
\end{abstract}

Key words: Children, Marriage, negative consequences

Source of funding: Nil Conflicts of interest: None declared

Knowledge Attitude and Practices (KAP) towards child marriage among married women residing in Nandyal - A Qualitative study

\section{Introduction}

Globally, child marriage (CM) is defined as marriage before the age of 18 years which applies to both boys and girls (1).However in India, as per 'Prohibition of Child Marriage Act 2006', a marriage is legally considered as CM when girl is less than 18 years old or boy is less than21 years old.(2) In 2007, United Nations Children's Fund (UNICEF) reported that a girl under the age of 15 is five times more likely to die during pregnancy and childbirth than a woman in her 20s(3) Most importantly, early marriage bereaves young girls of their childhood by overburdening them with domestic responsibility, motherhood, and sexual relations rather than allowing them to play with friends, go to school, and dream about a career (4)

Child marriage is any marriage that occurs before the age of 18 years, a standard that is reinforced by a general consensus among various international conventions and human rights agreements (5).Marriage is regarded as a moment of celebration and a milestone in adult life throughout the world. Indian society is marked by gender stratification and differentiation. Gender differences are reflected in the division of labour, where women bear the reproductive activities, while men primarily engage in productive activities. As a result, men often control and restrict women's access to resources (6). 
The imposition of a marriage partner upon a child means that a girl or boy's childhood is cut short and their fundamental rights are compromised. The custom survives of giving very small children away in marriage. On the auspicious day of Akha Teej, the mass solemnization of marriages between young boys and girls is performed. From the parents' point of view, this is the tried and tested way of organizing the passing on of property and wealth within the family (7).

\section{Methods and Materials}

A community based cross sectional study was done in urban slums of Nandyal. The primary objective of the study was to assess women's knowledge, attitude and practice towards child marriage who were married before age of 18years. The secondary objective was to know the association between the child marriages and their consequences. The inclusion criteria of the study was women of reproductive age group (15-49years)who were married before 18 years of age and experienced marital life for at least 5 years and had at least 1 child birth.The reason for selection criteria was that she had a prenatal and postnatal experience that they have spent a considerable time in marital union. Those who are not willing to give consent and don't want to participate are excluded. A selection of the participants was done by random selection by door to door survey. Those who fulfil the criteria were included in the study. Participants are informed about the study by participant information sheet was given and consent was taken from them. An in-depth interview was conducted by using a pre-tested semi structured questionnaire. The study period was August to September 2015. Data was entered in excel sheet and analysed by using SPSS 17.0 version. Data was shown as frequency tables and association was shown in significance by using chi-square test.

\section{Results}

A total of 30 participants were included in the study. The age of the participants ranges from 20 to 41 years. All of them were married between the age 11 and 17 years. The mean and standard deviation for age at

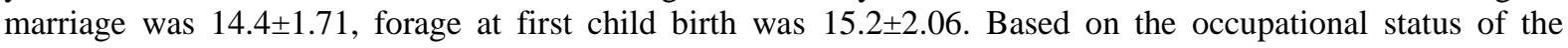
participants and their husbands, $13.3 \%(n=4)$ belonged to a low socio-economic class. $63.3 \%(n=19)$ belonged to upper lower socio-economic class, $20 \%(\mathrm{n}=6)$ belongs to lower middle class and $3.3 \%(\mathrm{n}=1)$ belonged to upper middle class. The majority of the participants $(\mathrm{n}=11 ; 36.7 \%)$ were uneducated. About $16.7 \%(\mathrm{n}=5)$ respondents had up to primary education, $13.3 \%(n=4)$ had middle school education, $26.7 \%(n=8)$ had up to high school education and $(n=2) 6.7 \%$ had up to intermediate. Majority of the participants $(86.7 \%, n=26)$ were stopped education after marriage and only $4 \%(n=4)$ of the participants were continued education even after marriage.

\section{Knowledge, Attitude and Practice towards child marriage}

Majority of the participants $83.4 \%(n=25)$ were doesn't have the knowledge regarding the child marriage, only $16.6 \%(n=5)$ know about the child marriage.Majority of the participants $73.3 \%(n=22)$ were not aware of negative consequences of child marriage and $26.7 \% \quad(n=8)$ were aware of the negative consequences.Most of the participants60\% $(n=18)$ were not aware of legal age for marriage and $40 \%(n=12)$ were aware of legal age for marriage.Most of the participants $83.3 \%(n=25)$ were not aware of criminal law against child marriage and only $16.7 \%(n=5)$ were aware.

None of the parentdoesn't have the perception on harmful effects towards child marriage.Majority of the participants $n=22(73.3 \%)$ don't have the future intention of child marriage. There is asignificant relationship between attitude and future intention of their child to be married early. Participants who are supporting $(n=7)$ child marriage are having their intention abandoning their children also. Participants who are against child marriage $(n=21)$ don't have the future intention of child marriage.

Almost $40 \%(n=12)$ of the participants are having consanguineous marriage and60 \%( $n=18)$ are nonconsanguineous marriage.Among 13 participants30\%(9)are having conflicts in their life, $6.7 \%(2)$ were divorced and $6.7 \%$ ( 2) were widowed.Majority $60 \%(\mathrm{n}=18)$ of the participants had their first delivery at home and $40 \%(n=12)$ had at hospital.Amongst total live births $(n=19)$ preterm and the remaining $(n=11)$ are term babies.Participants of $33.3 \%(n=10)$ having less than $2.5 \mathrm{~kg}$ of birth weight oftheir first child, $23.3 \%(n=7)$ are more than $2.5 \mathrm{~kg}, 43.4 \% \mathrm{n}=13$ don't know the birth weight of child.Almost all the participants don't have the individual ability of selecting their partners. Amongst $60 \%$ of the partner selection was done by both parents, $26.7 \%$ are by their father and $13.3 \%$ are by mother. There are different reasons for early marriage $40 \%(n=12)$ told, it was my parents decision, $26.7 \%(n=8)$ told for protection, $23.3 \%(n=7)$ told for protecting their family honour, $10 \%(\mathrm{n}=3)$ told to avoid attraction between male and female.Majority $60 \%(\mathrm{n}=18)$ were satisfied with their married life and $40 \%(n=12)$ were not satisfied 


\section{Discussion}

Based on the occupational status of the participants and their husbands, $13.3 \%(n=4)$ belonged to a low socio-economic class. $63.3 \%(n=19)$ belonged to upper lower socio-economic class, $20 \%(n=6)$ belongs to lower middle class and $3.3 \%(\mathrm{n}=1)$ belonged to upper middle class. In a study done by Pandya and Bhanderi Only $8.2 \%$ couples were in category I and $1.3 \%$ in category $\mathrm{V}$ of socioeconomic class according to modified Prasad's classification Educationhas been delineated as single most important protective factor against CM by many researchers. No or less education has been consistently related with higher prevalence of CM in different regions of India as well as in other countries. $(8,9,10)$ The majority of the participants $(n=11 ; 36.7 \%)$ were uneducated. About $16.7 \%(\mathrm{n}=5)$ respondents had up to primary education, $13.3 \%(\mathrm{n}=4)$ had middle school education, $26.7 \%(\mathrm{n}=8)$ had up to high school education and $(\mathrm{n}=2) 6.7 \%$ had up to intermediate. Majority of the participants $(86.7 \%, \mathrm{n}=26)$ were stopped education after marriage and only $4 \%(\mathrm{n}=4)$ of the participants were continued education even after marriage. School teachers can play a key role in preventing CM not only by educating children about their rights and concerns related to $\mathrm{CM}$, but also by providing assistance to the Child Marriage Prohibition Officer, as mentioned in section 16 of Child Marriage Act, 2006(11). In the present study participants were married before the age of 18 years. Out of all $(n=30)$ participants majority $(53.3 \%)$ were married before the age of 15 years. Majority are gave first child birth at the age of 15 years. In a study done by Pandey \& Singh age at the time of marriage was $\leq 16$ years (39\%)(13).At this age girl is not physically developed to give child birth. This in turn leads to morbidity and mortality. A study done by Pandya and Bhanderi, 98 women had at least one child. About half of them gave birth to their first child between the age of 16 and 20 years .Age at birth of first child was significantly different in mothers with and without $\mathrm{CM}(P<0.001)$.In our study $83.4 \%$ were don't have the knowledge about child marriage. A study done by pandya and Bhanderi Correct knowledge about the effect of early marriage on child's health Yes 11 (37.9) No 84 (65.1) In this study no single parents has knowledge about negative consequences of child marriage. Early and child marriage creates a number of negative consequences for young adults and their families. Of these, the development sector currently focuses on two primary impacts: on education, as girls are forced to drop out of school; and on the health of young women, especially linked to early pregnancy (12)Participants who are supporting $(n=7)$ child marriage are having their intention abandoning their children also. Participants who are against child marriage $(n=21)$ don't have the future intention of child marriage (Table 1). Almost $40 \%(n=12)$ of the participants are having consanguineous marriage and $60 \%(\mathrm{n}=18)$ are non-consanguineous marriage. Among 13 participants30 $\%$ ( 9) are having conflicts in their life, $6.7 \%$ (2) were divorced and $6.7 \%(2)$ were widowed. Majority $60 \%($ $\mathrm{n}=18)$ of the participants had their first delivery at home and $40 \%(\mathrm{n}=12)$ had at hospital. Amongst total live births $(\mathrm{n}=19)$ preterm and the remaining $(\mathrm{n}=11)$ are term babies. Participants of $33.3 \%(\mathrm{n}=10)$ having less than $2.5 \mathrm{~kg}$ of birth weight of their first child, $23.3 \%(\mathrm{n}=7)$ are more than $2.5 \mathrm{~kg}, 43.4 \% \mathrm{n}=13$ don't know the birth weight of child (Table2). In a Study done by Pandya\&Bhanderi, based on type of delivery [N=98] Full term was 48 (57.8) Preterm was 13 (86.7) and Birth weight $[\mathrm{N}=98]<2.5 \mathrm{~kg} 22$ (78.6) $\geq 2.5 \mathrm{~kg} 39$ (55.7) women with $\mathrm{CM}$ were found to deliver preterm babies and LBW babies at significantly higher proportion than women without CM $(P<0.05)$. Almost all the participants don't have the individual ability of selecting their partners. Amongst $60 \%$ of the partner selection was done by both parents, $26.7 \%$ are by their father and $13.3 \%$ are by mother. The vast majority had husbands more than five years older than themselves(14).In the present study also husbands are far elder than their wife (5-10 years).There are different reasons for early marriage $40 \%(\mathrm{n}=12)$ told, it was my parents decision, $26.7 \%(\mathrm{n}=8)$ told for protection, $23.3 \%(\mathrm{n}=7)$ told for protecting their family honour, $10 \%(\mathrm{n}=3)$ told to avoid attraction between male and female(Table 3). In a report they identified seven root causes of early and child marriage: the economics of marriage; sexuality; gender norms and masculinity; educational and institutional gaps; the centrality of marriage; risk, vulnerability and uncertainty; and age as an axis of power. (12)Majority 60\% ( $\mathrm{n}=18)$ were satisfied with their married life and $40 \%(\mathrm{n}=12)$ were not satisfied

\section{Limitations \& Recommendations}

As the study sample size was too small, the prevalence of the child marriage was not generalized to different populations. Raising the level of awareness about negative outcomes of child marriage by intensifying the Health education (IEC) activities. Implementing and enforcing stringent laws against child marriage practice. Promoting civil, sexual and reproductive health rights for women. Provision of economic opportunities for women can help to eliminate the child marriage practice.

\section{Conclusion}

Mean age of child marriage is 14 years. Mean age at first child birth is 15years. Majority (86.7\%) are stopped education after marriage. Upper lower class $63.3 \%$ \& lower class $13.3 \%$. Majority (73.3\%) are unaware of negative consequences of child marriage. Unaware of appropriate age for marriage (56.7\%). Most of the marriages are consanguineous (40\%). Majority $(60 \%)$ are home deliveries \& pre term deliveries $(46 \%)$. 
Majority (73.3\%) are opposing child marriage and $26.7 \%$ are supporting child marriage and having future intention. Satisfied with their married life $60 \%$ and $40 \%$ participants are having conflicts. More emphasis needs to be put on meeting the reproductive needs of poor adolescent mothers, and improving the nutritional status of their children, to break the vicious circle of poor reproductive health and poverty

Table 1:

\begin{tabular}{|c|c|c|c|}
\hline \multirow[t]{2}{*}{ Attitude towards child marriage } & \multicolumn{2}{|c|}{ FUTURE INTENTION } & \multirow[t]{2}{*}{ P-value } \\
\hline & YES (\%) & $\mathrm{NO}(\%)$ & \\
\hline SUPORTING & $7(23.4)$ & $1(3.3)$ & \multirow{3}{*}{$<0.001$} \\
\hline AGAINST & $1(3.3)$ & $21(70)$ & \\
\hline Total & $8(26.7)$ & 22(73.3) & \\
\hline
\end{tabular}

Table 2:

\begin{tabular}{|c|c|c|c|c|}
\hline \multirow[t]{2}{*}{ Place of delivery of first child } & \multicolumn{2}{|c|}{ Mode of delivery } & \multirow[t]{2}{*}{ Term } & \multirow[t]{2}{*}{ Preterm } \\
\hline & NVD & LSCS & & \\
\hline Home & $18(60.0)$ & 0 & 11(36.6) & $7(23.4)$ \\
\hline Hospital & $7(23.4)$ & $5(16.6)$ & $8(26.6)$ & $4(13.4)$ \\
\hline Total & $20(83.4)$ & $5(16.6)$ & $19(62.2)$ & $11(46.8)$ \\
\hline
\end{tabular}

Table 3:

\begin{tabular}{|l|c|}
\hline REASON FOR CHILD MARRIAGE & NO. OF INDIVIDUALS (\%) \\
\hline DECISION OF PARENTS & $12(40.0)$ \\
\hline PROTECTING FAMILY HONOUR & $7(23.3)$ \\
\hline AVOID ATTRACTION BETWEEN MALE AND FEMALE & $3(10.0)$ \\
\hline PROTECTION & $8(26.7)$ \\
\hline TOTAL & $\mathbf{3 0}(\mathbf{1 0 0 . 0})$ \\
\hline
\end{tabular}

[1]. (UNICEF. Child protection from violence, exploitation and abuse. Available from: http://www.unicef.org/protection/57929_58008.Html [Last accessed on 2014 Aug 21].)

[2]. (Government of India. Prohibition of Child Marriage Act, 2006. The Gazette of India. Ministry of Law and Justice, Government of India. Available from: http://wcd.nic.in/cma2006. Pdf [Last accessed on 2013 May 23].)

[3]. (UNICEF. The State of the World's Children 2007: Women and Children, the Double Dividend of Gender Equality. Available from: http://www.unicef.org/sowc07/docs/sowc07.pdf[Last accessed on 2014 Aug 21].)

[4]. Pandya YP, Bhandari DJ. An epidemiological study of child marriages in a rural community of Gujarat. Indian J Community Med 2015; 40:246-51.]5. Mathur, S., M. Greene, and A. Malhotra. Too Young to Wed: The Lives, Rights, and Health of Young Married Girls. Washington. DC: International Center for Research on Women. 2003.

[5]. Sgade 2005

[6]. Saxena, Shobha (1999), 'Who Cares for Child Marriages?' Pioneer, 29/1/99: ww.hsph.harvard.edu/grhf/Sasia/forums/childmar

[7]. Raj A, Saggurti N, Balaiah D, Silverman JG. Prevalence of child marriage and its effect on fertility and fertility-control outcomes of young women in India: A cross-sectional, observational study. Lancet2009; 373:1883-9.

[8]. International Union for the Scientific Study of Population. Trends and differentials in age at first marriage by caste in India Factors promoting marriages of girls. Available from:http://www.iussp.org/sites/default/files/event_call_for_papers/IUSSP\%20New.Extended\%20Abstract\%20ONE_0.pdf [Last accessed on 2014 Aug 21].

[9]. Das NP, Dey D. Female age at marriage in India: Trends and determinants. Demogr India 1998; 27:91-115.]

[10]. . (Government of India. Prohibition of Child Marriage Act, 2006. The Gazette of India. Ministry of Law and Justice, Government of India. Available from: http://wcd.nic.in/cma2006. Pdf [Last accessed on 2013 May 23].)

[11]. EARLY AND CHILD MARRIAGE IN INDIA A Landscape Analysis NIRANTAR TRUSTSupported by American Jewish World Service 2014

[12]. Pandey and Singh BMC Public Health (2015) 15:1316DOI 10.1186/s12889-015-2652-y

[13]. Hotchkiss et al. BMC International Health and Human Rights (2016) 16:6DOI 10.1186/s12914-016-0081-3 